\title{
Herramientas para la planeación estratégica en microempresas
}

\author{
RODOLFO VARGAS VALLECILLA
}

\section{RESUMEN}

El siguiente artículo trata en forma general el proceso para desarrollar una planeación estratégica enfocada a resultados en pequeñas empresas y microempresas. Con ejemplos muestra cómo se debe recoger la información que se necesita para realizar un análisis acertado en la toma de decisiones.

\section{PALABRAS CLAVE}

Planeación estratégica, mercado, competencia, costos, estrategia, objetivos estratégicos, misión, plan de mercadeo.

\section{ABSTRACT}

The following article is an overview about the process used to develop a strategic planning focused on results for small companies and micro enterprises. Through examples, it shows how to gather the information that is necessary to make an accurate analysis in the decision making.

\section{KEY WORDS}

Strategic planning, market, competition, costs, strategic objectives, strategy, mission, marketing plan.
Años atrás se creía que la planeación estratégica era solo para grandes empresas, de hecho, hoy en día todavía encontramos libros especializados en el tema con ejemplos en su mayoría aplicados a macroempresas ${ }^{1}$.

Philip Kotler hace una somera mención de la importancia de la planeación estratégica en la pequeña empresa en su libro de Fundamentos de marketing ${ }^{2}$, pero no entra en detalles de cómo se debe hacer.

Sin embargo, para fortuna de todos aquellos microempresarios con visiones claras de su negocio, la planeación estratégica es una herramienta para todo tipo de empresas, y su aplicación busca a través de un análisis profundo de la empresa y de su entorno, encontrar estrategias efectivas que permitan cumplir los objetivos que se propongan.

Tras años de experiencia e investigación sobre el tema, y trabajando en una compañía de consultoría para pymes, se desarrolló una metodología de planeación estratégica sencilla y dinámica, cuya condición de contar con menos personal y un presupuesto justo para operar requiere de pasos firmes y seguros de crecimiento.

A continuación relaciono todos los pasos que se deben aplicar para la planeación estratégica efectiva:

1. Análisis de la situación de la empresa en los últimos años.

2. Análisis del mercado.

3. Análisis de la competencia.

4. Análisis de costos.

5. Análisis del entorno macro.

1 Ferrel, O. C. y Hartline, Michael D. (2006). Estrategia de marketing. México: Thompson, Tercera edición, Pág. 22 y Apéndice B.

2 Kotler, Philip y Armstrong, Gary (2003). Fundamentos de marketing. México: Pearson Educación, Sexta edición, Pág. 59. 
6. Pensamiento de los dueños.

7. Objetivos estratégicos.

8. Estrategia de la organización.

9. Planes por área de trabajo.

\section{ANÁLISIS DE LA STTUACIÓN DE LA EMPRESA EN LOS ÚLTIMOS AÑOS}

Para este análisis se requiere recopilar información numérica de la empresa en por lo menos tres o máximo cinco años. Lo más sencillo es tener la información en Excel en tablas que registren:

- Ventas de la empresa

- Ventas por ciudad

- Ventas por línea de productos

- Ventas por producto

- Ventas por vendedor

- Ventas por distribuidor

La clave para todo el análisis es tener información en bases de datos que permitan manejarla en forma eficiente. Fernando Dávila en su libro Gestión de la información lo ilustra de la siguiente forma:

La manera natural para el manejo de la información son las bases de datos. Para lograr un eficiente uso de ellas en Excel, es fundamental plantear las soluciones a los problemas de una manera organizada y con un diseño correcto, que nos permita aprovechar todas las posibilidades de Excel $^{3}$.

Un ejemplo de cómo se recoge la información se muestra en la Tabla 1.

La forma más fácil de analizar esta información es graficándola como se muestra en el Gráfico 1. Así se verían las ventas de un vendedor.

Una vez se ha recopilado toda la información para el análisis de la situación actual, se procede con el siguiente paso del análisis del mercado.

En el trabajo que realizamos en el Politécnico Grancolombiano en el 2007, usamos el software Admoney ${ }^{4}$ que facilitó la recolección de toda la información comercial necesaria para el análisis.

\section{ANÁLISIS DEL MERCADO}

Cuando decimos análisis del mercado, nos referimos a los compradores tanto actuales como potenciales de los productos que vende la empresa.

Este análisis debe responder las siguientes preguntas básicas:

1. ¿Tenemos clientes o compradores?

2. ¿Cuánto compran de cada producto? (Tamaño del mercado).

3. ¿Cómo crece el mercado por producto?

4. ¿Qué características los identifican: demográficas, geográficas, sectores, etcétera?

5. ¿En el proceso de compra hay compradores, usuarios o influenciadores?

6. ¿Qué importancia tiene nuestro producto para los clientes? ¿Es fundamental para ellos o es un producto complementario?

7. ¿Cómo compran: mensual, semestral, anual, o de otra forma?

8. ¿Dónde lo compran: directamente con nosotros o a través de los distribuidores?

9. ¿Por qué eligen los clientes los productos de la empresa?

10. ¿Hay fidelidad de los clientes?

11. ¿Por qué los posibles clientes no eligen los productos de la empresa?

12. ¿Qué planes al futuro tienen nuestros clientes, donde nosotros podamos participar?

\section{Rodolfo Vargas Vallecilla.}

Ingeniero Mecánico de la Universidad Nacional, Especialista en Administración de Empresas de la

Universidad del Rosario, Especialista en Comercio Internacional de la Universidad Jorge Tadeo Lozano, Gerente de Proyecto de Business Partner Consulting, catedrático del Politécnico Grancolombiano en las materias de Plan de Mercadeo y Gerencia de Mercadeo.

Para contactar al autor: rvargasv@poligran.edu.co o | rodolfovargasv@hotmail.com

3 Dávila Ladrón de Guevara, Fernando (2002). Gestión de la información, guía práctica con Excel. Colombia: Alfaomega Colombiana, Primera edición, Pág. 1.

4 Programa que factura, hace control de inventarios, almacena costos de productos, vendedores y clientes y tiene otras herramientas adicionales para manejar administrativa y comercialmente una pequeña empresa. 


\section{Tabla No. 1. Ejemplo de cómo se debe tabular la información de ventas por vendedor}

\begin{tabular}{|l|r|r|r|r|r|}
\hline \multicolumn{7}{|c|}{$\begin{array}{c}\text { VENTAS } \\
\text { VENDEDOR } \\
\text { (Millones) }\end{array}$} \\
\hline Vendedores & \multicolumn{5}{|c|}{ Ventas } \\
\hline Nombre* & 2002 & 2003 & 2004 & 2005 & 2006 \\
\hline Vendedor 1 & 100 & 115 & 120 & 140 & 150 \\
\hline Vendedor 2 & 50 & 87 & 90 & 100 & 120 \\
\hline Vendedor 3 & 45 & 56 & 65 & 85 & 96 \\
\hline Vendedor 4 & 84 & 95 & 100 & 115 & 130 \\
\hline Vendedor 5 & 65 & 65 & 70 & 78 & 89 \\
\hline Vendedor 6 & 25 & 90 & 95 & 111 & 160 \\
\hline Vendedor 7 & 84 & 85 & 95 & 120 & 140 \\
\hline TOTAL & 453 & 593 & 635 & 749 & 885 \\
\hline * En orden alfabético & & & & & \\
\hline
\end{tabular}

\section{Gráfico No. 1. Ejemplo de cómo se grafican las ventas por vendedor}

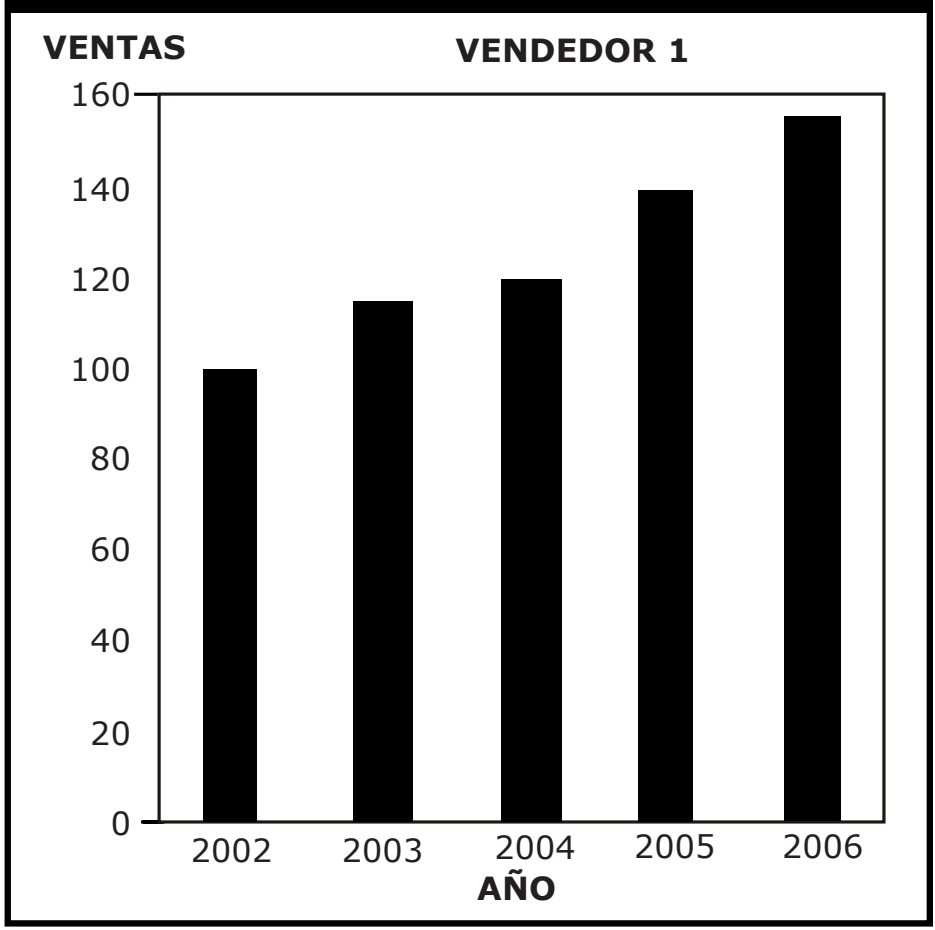

Estas son las preguntas iniciales para hacer un análisis del mercado. Dependiendo del producto o negocio, puede ser posible que surjan nuevas preguntas para completar el análisis.

\section{ANÁLISIS DE LA COMPETENCIA}

De igual forma, para realizar el análisis de la competencia, debemos responder una serie de preguntas que nos faciliten el proceso:

1. ¿Quiénes son nuestros principales competidores? Nombre, productos, marcas, tamaño (ventas).

2. ¿Qué estrategias usan?

3. ¿Cuál es su participación en el mercado?

4. ¿Es fácil que entren nuevos competidores?

Seguramente también surgirán otras preguntas en la dinámica del análisis y harán más eficaz los resultados.

\section{ANÁLISIS DE COSTOS}

Para la realización de este punto, también es necesario conseguir, en tablas de Excel, información interna de la empresa que nos facilite el análisis, y, de igual forma, usamos el software Admoney para extraer la información.

Los costos que deben ir en las tablas son los variables, de forma que podamos obtener la utilidad bruta que genera cada producto y su margen bruto de rentabilidad. En la Tabla 2 vemos un ejemplo de esto. De esta forma es fácil percibir cuáles son los productos más rentables para la organización.

\section{ANÁLISIS DEL ENTORNO MACRO}

Aquí se revisan qué variables de tipo económico, político, cultural o tecnológico pueden afectar positiva o negativamente a la empresa. Toda la información para este análisis se recopila de fuentes secundarias. Por ejemplo, ¿qué influencia puede tener el T.L.C. en la compañía? 


\section{PENSAMIENTO DE LOS DUEÑOS}

Con los dueños de la empresa se analizará si tienen clara la Misión de la organización, cuál es el rumbo que quieren para la empresa, qué proyectos tienen, y si quieren lanzar nuevos productos. La reunión con los dueños servirá para definir los objetivos estratégicos de la empresa.

\section{OBJETIVOS ESTRATÉGICOS}

En este aparte definimos cuáles van a ser los objetivos estratégicos a corto y mediano plazo que quieren los dueños de la empresa. Los objetivos se deben especificar en términos medibles, alcanzables y que tengan un tiempo determinado. Se debe tener claro qué tipo de objetivos quieren los dueños de la organización: rentabilidad, crecimiento, posicionamiento, etc. Por ejemplo, una vez estimado el potencial del mercado, se puede plantear un objetivo estratégico de crecimiento en ventas para uno o dos años.

\section{ESTRATEGIA DE LA ORGANIZACIÓN}

Una vez que se definen los objetivos estratégicos, se debe estudiar cuál debe ser la estrategia de la organización y cómo se van a lograr los objetivos estratégicos propuestos.

La estrategia de la empresa se analiza a la luz de la matriz producto-mercado, cuyo uso lo explica O. C. Walker Jr. en su libro Marketing Estratégico ${ }^{5}$.

Con base en la estrategia que se determine, se debe realizar el plan de mercadeo para cumplir con los objetivos estratégicos. La matriz producto - mercado se ilustra en el Gráfico 2.

\section{PLANES POR ÁREA DE TRABAJO}

Una vez definida la estrategia de la organización, se debe plasmar en los diferentes planes por realizar para lograr los objetivos.
Para el caso específico del área de mercadeo y ventas de la empresa, el plan que se debe llevar a cabo es un plan de mercadeo.

Un plan de mercadeo debe tener los siguientes elementos mínimos:

1. Objetivo del plan.

2. Estrategia de mercadeo.

3. Plan de trabajo.

4. Presupuesto.

5. Sistema de control.

Los objetivos del plan de mercadeo generalmente se especifican en términos de ventas anuales, aunque pueden haber otros. Estas ventas tienen que ser congruentes con los objetivos estratégicos de la empresa.

La estrategia de mercadeo será un conjunto de acciones que se deberán realizar sobre el producto, los precios, la comunicación y sobre la forma de distribución del producto.

Para que la ejecución de la estrategia sea fácil de implantar, es necesario plasmarla en un plan de trabajo que especifique qué acción se va a realizar, cómo se debe realizar la acción, quién es el responsable, cuánto tiempo dura y cuánto costaría ejecutarla. Una guía para desarrollar un plan de trabajo se muestra en la Tabla 3.

Una vez que se determine el plan de trabajo, es más sencillo establecer el presupuesto de gastos de mercadeo, dado que en el plan de trabajo se estima el costo de ejecución de las acciones que se van a llevar a cabo.

Para que el plan funcione, es necesario desarrollar un sistema de control que garantice la correcta implantación del mismo. Para controlar la ejecución, se deben desarrollar básicamente dos tipos de indicadores: indicadores de gestión que van a monitorear la ejecución de las acciones y los de resultado que van a monitorear el logro de los objetivos propuestos.

5 Walker, O. C. Jr., Boyd, Harper, Mullins, John y Larréché, Jean-Claude (2004). “Decisiones de estrategia corporativa y sus implicaciones de marketing”. En: Marketing Estratégico. México: McGraw-Hill, capítulo IV, Cuarta edición, Pág. 49. 
Tabla No, 2. Ejemplo de tabulación de cifras para analizar rentabilidad

\begin{tabular}{|l|r|r|r|r|}
\hline Producto & \multicolumn{1}{|c|}{$\begin{array}{c}\text { Precio de } \\
\text { venta }\end{array}$} & \multicolumn{1}{c|}{$\begin{array}{c}\text { Costo } \\
\text { variable }\end{array}$} & \multicolumn{1}{|c|}{$\begin{array}{c}\text { Utilidad } \\
\text { bruta }\end{array}$} & \multicolumn{1}{c|}{$\begin{array}{c}\text { Margen } \\
\text { bruto }\end{array}$} \\
\hline Producto 1 & $\$ 1.000$ & $\$ 700$ & $\$ 300$ & $30 \%$ \\
\hline Producto 2 & $\$ 2.500$ & $\$ 1.500$ & $\$ 1.000$ & $40 \%$ \\
\hline Producto 3 & $\$ 1.800$ & $\$ 1.500$ & $\$ 300$ & $17 \%$ \\
\hline
\end{tabular}

\begin{tabular}{|c|c|c|}
\hline \multicolumn{3}{|c|}{$\begin{array}{l}\text { Gráfico No. 2. Matriz de } \\
\text { producto - mercado* }\end{array}$} \\
\hline & $\begin{array}{c}\text { Productos } \\
\text { actuales }\end{array}$ & $\begin{array}{c}\text { Nuevos } \\
\text { productos }\end{array}$ \\
\hline $\begin{array}{l}\text { Mercado } \\
\text { actual }\end{array}$ & $\begin{array}{l}\text { Estrategia de } \\
\text { penetración de } \\
\text { mercado }\end{array}$ & $\begin{array}{l}\text { Estrategia de } \\
\text { desarrollo de } \\
\text { producto }\end{array}$ \\
\hline $\begin{array}{l}\text { Nuevos } \\
\text { mercados }\end{array}$ & $\begin{array}{l}\text { Estrategia de } \\
\text { desarollo de } \\
\text { mercado }\end{array}$ & $\begin{array}{l}\text { Estrategia de } \\
\text { diversificación }\end{array}$ \\
\hline $\begin{array}{l}\text { * Fuente: A } \\
\text { Pamplona: }\end{array}$ & $\begin{array}{l}\text { Igor (1976). La } \\
\text { w Hill, Pág.123 y }\end{array}$ & ategia de la em \\
\hline
\end{tabular}

\section{Tabla Nº. 3. Ejemplo de un plan de trabajo}

\begin{tabular}{|c|c|c|c|c|}
\hline Acción & $\begin{array}{c}\text { Cómo } \\
\text { se hace }\end{array}$ & Responsable & $\begin{array}{c}\text { Tiempo de } \\
\text { ejecución }\end{array}$ & Costo \\
\hline Acción 1 & & & & \\
\hline Acción 2 & & & & \\
\hline Acción ... & & & & \\
\hline
\end{tabular}

\section{BIBLIOGRAFÍA}

- DÁVILA L. DE G. Fernando (2002). Gestión de la información. Colombia: Alfaomega Colombiana, Primera edición.

- WALKER, O. C. Jr.; BOYD, Harper; MULLINS, John y LARRÉCHÉ, Jean-Claude (2004). Marketing Estratégico. México: McGraw Hill, Cuarta edición.

- FERRELL, O. C. y HARTLINE, Michael (2006). Estrategia de marketing. México: Thompson, Tercera edición. - GUILTINAN, Joseph, GORDON, Paul y MADDEN, Thomas J. (1998). Gerencia de marketing, estrategias y programas. Colombia: McGraw Hill, Sexta edición.

- KOTLER, Philip y ARMSTRONG, Gary (2003). Fundamentos de marketing. México: Pearson Educación, Sexta edición.

- ANSOFF, Igor (1976). La estrategia de la empresa. Pamplona: McGraw Hill. 